\title{
Institutional Impediments To Voluntary Ethics Measurement Systems: An International Perspective
}

O. Scott Stovall, Abilene Christian University, USA John D. Neill, Abilene Christian University, USA Brad Reid, Abilene Christian University, USA

\begin{abstract}
Despite numerous appeals in the business ethics literature for a multiple-stakeholder perspective to corporate governance, in practice the widespread adoption of voluntary ethics measurement systems that consider multiple stakeholders remains elusive. In this paper, we employ an institutional economics framework to examine the legal environment in several English-speaking countries in order to determine potential constraints that might cause managers to avoid the adoption of such systems. Our findings indicate that in British Commonwealth countries (1) the courts tend to view stockholders as the primary corporate constituency group and (2) there is a lack of documentary privilege. Therefore, any internally generated metrics on ethics and corporate social responsibility matters could potentially be either trivialized or used against the corporation in court proceedings. Before adopting a voluntary ethics measurement system, managers should be aware of these and other potential institutional constraints that may impede such efforts.
\end{abstract}

\section{INTRODUCTION}

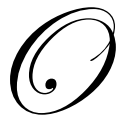

ver the last twenty years or so, there have been numerous calls in the business ethics literature for a move toward a multiple-stakeholder perspective. To illustrate the pervasiveness of the stakeholder perspective, Donaldson \& Preston (1995, p. 65) state that "since the publication of Freeman's landmark book, Strategic Management: A Stakeholder Approach (1984), about a dozen books and more than 100 articles with primary emphasis on the stakeholder concept have appeared." By implication, such appeals for a multiplestakeholder perspective would result in a movement away from the viewpoint that stockholders are the only legitimate corporate constituency with which managers should be concerned. However, such calls for a widespread adoption of the multiple-stakeholder approach have not yet occurred in the business community. In this paper, we seek to uncover some potential reasons why measurement and reporting of corporate social responsibility (CSR) and ethics metrics are not as pervasive as some theoreticians in the business ethics field would like.

In a previous study, we argued that advocates of voluntary ethics measurement systems have generally ignored various constraints that institutions place upon managers that attempt to quantify ethical and CSR considerations (Stovall et al., 2006). In that earlier work, we identified two institutional constraints that may impede managers' attempts to measure and consider CSR and ethics in their decisions. These institutional impediments are (1) neoclassical economic theory and (2) the United States' legal system.

We previously argued that both business education and legal precedent utilize neoclassical economic theory in order to justify the legitimacy of treating shareholders as the primary corporate constituency group. In the United States, the tenet that a corporation exists to maximize shareholder wealth remains largely sacrosanct in business education. Also, while the results of our legal research were somewhat mixed, in general we found U.S. case law that utilized private property rights to support the shareholder wealth maximization principle. By supporting 
neoclassical economic theory, private property rights, and shareholder primacy, the U.S. legal system potentially hinders implementation of measurement systems that address the needs of multiple stakeholder groups.

Interestingly, we also discovered several cases that upheld management and director efforts to enhance the welfare of corporate constituencies other than shareholders if and only if such efforts fulfilled a legitimate business purpose. The courts often refer to this principle as the "the business judgment rule." U.S. courts sometimes employ this principle to rule for managers in shareholder suits involving the distribution of corporate resources for socially responsible expenditures. For example, on several occasions, courts ruled that charitable contributions made by corporations were acceptable if one could argue that making such contributions increased shareholder wealth by enhancing the corporation's image.

We also previously argued that the threat of litigation by various potentially interested parties may constrain corporate managers from measuring and considering ethics and CSR matters. That is, corporations might hesitate to adopt measurement systems that capture ethical considerations such as work force diversity or safety issues for fear that such data might be used against the corporation in future litigation. In our prior research, we found that a legal concept sometimes referred to as "the privilege of self-critical analysis" is often ignored by U.S. courts in civil litigation, thereby making this threat legitimate. Specifically, when corporations capture information internally about various CSR and ethics issues that may be of interest in litigation, such information is generally not afforded legal privilege and is therefore admissible as evidence against the corporation. In the previous paper, we suggested that corporations could involve outside counsel in the development and maintenance of ethics measurement systems in order to employ attorney-client privilege and thus ameliorate this potential threat.

In this study, we extend our prior research into the international realm. In particular, we examine the extent to which the previously documented institutional barriers to quantifying ethical and CSR concerns in the United States exist in other countries as well. We also seek to determine if other institutional constraints are present in nonU.S. countries that we did not find in the U.S. context. In our opinion, it is important to extend this line of research by adopting an international perspective, because as multinational corporations expand their operations and influence across the globe, managers must understand the operating environments of countries besides their own. It is probable that other countries and cultures possess an environment that is more or less tolerant of a multiplestakeholder perspective of corporate governance, and therefore potentially more or less tolerant of the adoption, implementation, and maintenance of ethics and CSR measurement systems.

The remainder of this paper is organized as follows. First, we discuss the relevance of institutional economic theory in the identification and analysis of the potential constraints that managers face as they contemplate the adoption of a voluntary ethics measurement system. Second, we discuss our research methodology and the results of our international legal analysis. Finally, we provide some implications of the research findings.

\section{INSTITUTIONAL ECONOMICS}

Institutional economic theory provides an interesting and profitable framework with which to identify and analyze potential constraints to voluntary ethics and CSR measurement systems. Institutional economists suggest that individual and social processes of obtaining and interpreting information, such as making economic choices, are "closely related to the norms, conventions, and routines of social culture and institutions" (Hodgson, 1988, p. 8). According to institutional economics, when developing a theory about how individuals derive preferences and make choices, one must identify and understand the institutions that shape and often constrain individuals' experiences. Hodgson (1988, p. 132) explains:

The critical point is that both routines and formal institutions, by establishing more or less fixed patterns of, or boundaries to, or regulations over, or constraints upon, human action, actually supply information to other agents. Such inflexibilities or constraints actually suggest to the individual what other agents might do, and the individual can then act accordingly.

While institutions serve to influence and potentially constrain choices, institutional theory in the classical sense also includes the notion that economic analyses and outcomes need not be deterministic (Veblen, 1899). 
Unlike their neoclassical counterparts who view economic behavior largely as the result of innate responses to selfinterest, institutional economists suggest that economic actors can shape outcomes to address social problems and objectives. Such change sometimes occurs as an evolutionary process, such as how the gradual modification of language shapes perception and then behavior. From an institutional economics perspective, change may also occur more radically as the result of a cataclysmic failure of a social institution. An example of such a social institution failure is the preponderance of accounting scandals that occurred at the beginning of this decade. Hodgson (1988, p. 139) expresses this idea by suggesting that "institutions change, and even gradual change can eventually put such a strain on a system that there can be outbreaks of conflict or crisis, leading to a change in the actions and attitudes."

Institutional economists therefore not only suggest that language serves as a powerful force in establishing and maintaining the "norms, conventions, and routines" referred to above, but also that the economic language that we use may be shaped over time to ameliorate social problems. As an example, education and other institutions can serve to shape public perceptions as to what economic analysis and activity should include. That is, a shareholder dominant view of corporate governance need not remain unchanged. Through the use of education, the courts, and other institutional forces, a multiple-stakeholder view of corporate governance may eventually be legitimized, just as over time the shareholder dominant viewpoint has become reified in language and culture. In other words, a more inclusive view of corporate constituencies can be promoted and maintained by employing some of the same institutions and language that have historically been used to promote the narrow, shareholder primacy view of corporate governance. If as educators, academicians can (1) understand how institutions influence the norms, conventions, and accepted behavior among actors in society, (2) see societal problems that may result from such phenomena, and (3) help shape institutions in order to address such problems, institutional economists would suggest that the academic community has a responsibility to "help" those institutions evolve to benefit society at large.

\section{RESEARCH METHODOLOGY AND RESULTS}

\section{Methodology}

It is important to note at the outset that besides some anecdotal evidence from two non-English-speaking countries that we report on later in the paper, we have limited our research to the legal environments within Englishspeaking, primarily British Commonwealth countries. There are several reasons for this somewhat narrow focus. First, our language skills, or more accurately the lack thereof, prohibit us from engaging in research in languages other than English. Second, our access to case and statutory law is largely limited to countries with a British legal heritage. We hope that this research will serve to motivate others to investigate similar issues in non-Englishspeaking cultures.

In order to answer the question as to whether the same institutional impediments that we documented in the U.S. context exist in other English-speaking countries, we conducted legal research to examine both precedent set forth in case law and relevant statutory law. First, we report on our analysis of the case and statutory law that provides legitimacy to various corporate constituencies. That is, our first research question is: Does the law in the countries that we selected for review establish primacy for any specific group of corporate stakeholders, in the same manner that U.S. case law employs neoclassical economic theory and private property rights to assert the rights of shareholders over other groups? Second, we provide the results of our review of case and statutory law that addresses legal precedent relevant to concluding whether a company may be subject to litigation risk by measuring and reporting ethics and CSR activities, as is the case in the U.S.

\section{Results Regarding The Legitimacy Of Various Corporate Constituencies}

In our search of relevant legal cases in British Commonwealth countries, we identified two lawsuits that resulted from a corporation's CSR activities in which they distributed corporate resources to stakeholders other than stockholders. Both of these cases are older, English cases. In Prescott v. Birmingham Corporation (1954), a transit authority provided free transportation to the elderly, and several parties brought suit complaining that this was an inappropriate use of corporate funds. In this case, providing such benevolence to elderly customers was held by the English court to be ultra vires (i.e., beyond the power of the corporation). In dicta, Justice Jenkins stated that if a 
corporation "omit[ed] to exact the toll which is the consideration for the service, the shareholders would seem to be the only persons who can have a right to complain" (Prescott v. Birmingham Corporation, 1954, p. 14). While not specifically addressing the merits of the complaint, since apparently the shareholders did not bring the suit, Justice Jenkins' comments indicate that a stockholder's claim against a corporation for giving away corporate profits would have a legal basis. This result is consistent with the notion that the management of a corporation has a fiduciary duty to the stockholders and it is beyond managements' authority to distribute corporate profits to other constituencies, even in a benevolent manner.

In Parke v. Daily News (1962), the board of directors was found to have wrongfully authorized payments to laid-off employees without shareholder approval. This decision led to British legislation authorizing the directors of companies to make payments to laid-off employees "not withstanding that its exercise is not in the best interests of the company" (English Companies Act, 1985). It is interesting to note that the Parke v. Daily News decision cited the classic U.S. case, Dodge v. Ford Motor Co., for the proposition that "gifts will accordingly be permitted only when they tend, either directly or indirectly, to benefit the company in some genuine manner" (Parke v. Daily News, 1962, p. 9). The ruling in the Parke v. Daily News case also indicates that the English courts would likely uphold a shareholder lawsuit against the management of a corporation for distributing corporate profits, even for charitable purposes. One exception to the general rule would occur in the case of employee severance payments that are now allowed under the Companies Act, as discussed above. The court's ruling in the Parke v. Daily News case is consistent with our prior findings in the U.S. context that corporate profits may be distributed for CSR-related activities if and only if such distributions are for legitimate business reasons. To repeat the words of the decision, such corporate distributions would be permitted if and only if they "benefit the company in some genuine manner" (Parke v. Daily News, 1962, p. 9).

Our international legal analysis therefore reveals that the English courts tend to view the stockholder as the primary corporate stakeholder. However, an implication of our results is that corporate management may engage in CSR-related activities if they can justify their charitable and other socially responsible distributions as benefiting the corporation either directly or indirectly. In that manner they are fulfilling their fiduciary duty to shareholders as well as acting responsibly to other valuable corporate constituencies. This result parallels our U.S. findings that the "business judgment rule" may be used to justify CSR-related activities.

\section{Results Regarding The Potential Threat Of Litigation}

In this section, we will review both the relevant statutory law and case law relating to whether internally generated ethics and CSR-related measurements could be used against a corporation in a lawsuit in select Englishspeaking countries. If such measurements are indeed admissible in court proceedings, then corporate management would be reluctant to even attempt to measure and report these important constructs.

In terms of legislation, in the British Commonwealth there is a limited lack of documentary privilege. In Re L (1996) the English House of Lords decided that a report, otherwise privileged under attorney-client privilege, was not protected because it helped establish a standard for the proper care and protection of a child. Other recent developments in England, specifically Lord Woolf's access to Justice Report (HMSO, 1996) advocated that litigants be required to disclose all information not available to the other party. Arguably this improves litigation efficiency but simultaneously discourages parties from conducting their own internal investigations or employing a voluntary ethics measurement system. Similar arguments to Woolf's Report have been made in Canada concerning the mandatory disclosure of documents (Canadian Ministry of Supply and Services, 1997).

Precedent set forth in English case law also restricts documentary privilege. In Three Rivers District Council v. Bank of England (2003), documents that were prepared by bank employees in order to obtain legal advice that had not actually been sent to the solicitors were not privileged. This decision is frequently cited by British courts in denying privilege to internal documents. A similar rule was followed in tobacco litigation in England in U.S. v. Philip Morris, Inc., and Others (2004).

In Australian tobacco litigation (British American Tobacco Australia Services LTD v. Eubanks, 2004), a substantial amount of internal memoranda were deemed admissible into evidence, because either the information 
had been previously disclosed or because it was not directly prepared at the direction of legal counsel. In the course of the opinion, the Australian court noted that "the history of the Australian scheme indicates that the British case law should generally be followed in Australia" (British American Tobacco Australia Services LTD v. Eubanks, 2004, p. 41). Also, with respect to Canadian case law, in Prosperine v. Ottawa Carleton (2002, p. 7) the court determined that an in-house investigative report "to assess whether there had been any misconduct or inappropriate activity on the part of RMOC personnel, suppliers and contractors" was not privileged from disclosure.

Therefore, given the lack of documentary privilege in countries with a British legal heritage, the threat of litigation serves as a potential institutional impediment to measuring and reporting sensitive CSR efforts. That is, corporations in the English-speaking countries that we examined that internally measure and collect information regarding ethical issues may be subject to the threat that such information may be used as evidence against them in a court of law. This result is similar, and perhaps even more stringent, than the results we documented in the U.S. legal context.

At a recent international research conference we observed some anecdotal evidence of the threat of litigation as a potential impediment to ethics measurement and reporting systems in two non-English-speaking countries. First, and most dramatic, a director of corporate social reporting for a multinational corporation based in Germany expressed the concern that his job was complicated by restraints that his employer's legal department places on CSR reporting. Specifically, this individual indicated that there were a number of CSR issues that the company is not allowed to measure and report on because their in-house legal counsel is concerned about the very real threat of litigation that might result from such measurement and reporting.

Second, during our presentation of the results of this research at the same conference, a participant noted recent discussion in France regarding whether the French legal system should allow large class-action lawsuits against corporations similar to those allowed in the U.S. Apparently, among others, "French President Nicolas Sarkozy, Deutsche Telekom AG shareholders, and American lawyers" are "pushing for changes that encourage group litigation" (Byrne \& O'Reilly, 2007, p. 1). If successful, such a change allowing class-action lawsuits against corporations could potentially encourage plaintiff attorneys to search for information captured by CSR measurement and reporting systems in France. Such a change in the French legal system could therefore result in a reluctance of managers to measure and provide CSR and ethics metrics.

\section{CONCLUSIONS AND IMPLICATIONS}

Based upon our review of both statutory and case law in countries with a British legal heritage, we determined that the legal system in those countries serves as a threat to corporate managers and directors who wish to adopt voluntary ethics measurement systems. First, as was the case in our examination of the U. S. legal environment, courts in British Commonwealth countries generally support the viewpoint that shareholders are the primary corporate constituency. Neoclassical economic theory and private property rights serve as powerful forces that support the pursuit of the shareholder wealth maximization principle, thereby making the interests of other corporate constituencies such as employees, communities, and the environment secondary to shareholder interests. Therefore, it is likely that managers who are preoccupied with maximizing shareholder concerns would not be overly concerned with capturing information about, and making decisions based on the interests of, a varied group of stakeholders beyond the shareholders. In fact, in a legal and business environment that favors the interests of stockholders over other corporate constituencies, managers would typically only engage in CSR-related activities if such activities resulted in an increase in shareholder welfare.

Second, our findings related to the legal environments of several English-speaking countries beyond the U.S. support the notion that managers who would otherwise espouse and adopt voluntary ethics measurement systems should be concerned with the potential threat that information from such ethics measurement systems could be used in litigation brought against the companies they manage. That is, since ethics and CSR measurement systems typically capture information on sensitive issues such as workforce diversity, worker safety violations, and environmental degradation concerns, managers should be aware that such internally generated information is typically not afforded legal privilege in countries with a British legal tradition. Therefore the resulting measurements could potentially be used as evidence against the company in a legal action. This very real litigation 
threat may be more strident in the countries that we analyzed in this study than in the U.S. context, since even the attorney-client privilege held largely sacrosanct in the United States appears weaker in some other English-speaking countries. Of course, as we suggested in the previous study on the U.S. legal environment, managers could mitigate this threat somewhat by positively addressing environmental, safety, or other concerns that an ethics measurement system might reveal. However, such positive actions would not eliminate the threat of litigation resulting from activities that occurred before the changes were implemented.

The primary limitation of this study relates to the scope of the analysis. Beyond the anecdotal evidence we reported on about the proposed change in France that would allow class-action lawsuits against corporations and the reluctance of a German multinational's legal department to collect certain CSR-related metrics, we limited our investigation to the legal environments in countries with a British legal heritage. However, even after considering this scope limitation, the implications of our findings are significant for a number of reasons. First, while multinational corporations' operations expand and grow across numerous national borders, arguably the most important sources of equity capital remain concentrated in capital markets located in the U.S., Great Britain, and other English-speaking countries. It therefore seems likely that shareholder initiated litigation would occur most frequently in these countries. Second, as the globalization of business continues to take place, Western business and legal practices and traditions will likely continue to spread as well. It seems naïve to assume that the Western tradition of plaintiff-based legal action would be any different.

International proponents of voluntary ethics measurement systems must contend with the potential institutional legal threats that we have identified. However, as we discussed earlier, while institutional economics aided in our analysis of potential impediments of CSR and ethics measurement systems, an institutional economics perspective also suggests that such constraints might become less binding over time. As the norms related to economic language and attitudes about corporate constituencies change, the institutional barriers that we have documented also have the potential to change. While such change may be a slow process due to the concept of legal precedent, changing social and cultural attitudes have the ability to influence the legal system through the courts. Armed with institutional economic theory, proponents of voluntary CSR and ethics measurement systems need not be fatalistic about the possibility of future change.

\section{REFERENCES}

1. British American Tobacco Australia Services LTD v. Eubanks. 2004. NSWCA 158 (Supreme Court of New South Wales).

2. Byrne, C. \& O’Reilly, C. 2007. Sarkozy, U.S. lawyers shift class-actions to europe (Update3). http://www.bloomberg.com/apps/news?pid=newsarchive\&sid=aEM8mt1Xq3oo, July, 24.

3. Canadian Ministry of Supply and Services. 1997. 1997 Law reform commission of Canada's report on evidence.

4. $\quad$ English Companies Act. 1985. S 719(2).

5. Donaldson, T. \& Preston, L. 1995. The stakeholder theory of the corporation: Concepts, evidence, and implications. Academy of Management Review, 20: 65-91.

6. Freeman, R. 1984. Strategic management: A stakeholder approach. Boston: Pitman.

7. HMSO. 1996. Final report to the Lord Chancellor on the civil justice system in England and Wales.

8. Hodgson, G. 1988. Economics and institutions. Philadelphia: University of Pennsylvania Press.

9. $\quad$ Parke v. Daily News, LTD. 1962. Ch 927 (Chancery Division), June 6.

10. Prescott v. Birmingham Corp. 1954. 3 All E.R. 698 (Chancery Division and Court of Appeal), November 30.

11. Prosperine v. Ottawa Carleton (Regional Municipality). 2002. 2002 O.J. No. 3316 (Ontario Superior Court of Justice), August 28.

12. $\quad$ Re L. 1996. 2 All E.R. 78 (House of Lords), March 21.

13. Stovall, O., Neill, J. \& Reid, B. 2006. Institutional impediments to voluntary ethics measurement systems. Journal of Business Ethics, 66: 169-175.

14. Three Rivers District Council v. Bank of England. 2003. Q.B. 1556 (Q.B. 2003), April 3.

15. U.S. v. Philip Morris, Inc., and Others. 2004. EWCA Civ. 330 (Court of Appeal Civil Division), March 23. 
16. Veblen, T. 1899. The theory of the leisure class: An economic study of institutions. New York: Macmillan.

\section{AUTHOR NOTES}

${ }^{1}$ Our research revealed that the "business judgment rule" is broadly found in English common law nations, although we were unable to document it in the specific context of CSR activities. Specifically, our legal research revealed the court's use of the business judgment rule in Canada, Australia, Singapore, and England in more general contexts than CSR and ethics-related activities.

\section{NOTES}




\section{NOTES}

